\title{
Correspondence
}

Archives of Disease in Childhood, 1970, 45, 602.

\section{Carmine Dye and Salmonellosis}

Sirs,

This note is prompted by the article 'Carmine as an Index of Transit Time in Children with Simple Constipation' by S. B. Dimson in Archives, 45, page 232. Carmine dye is very convenient for the purpose mentioned, and has been widely used also to colour certain foods, drugs, and cosmetics. However, it should be pointed out that hospital outbreaks of salmonellosis (S. cubana) have been traced to contaminated batches of this naturally derived dye. The dye is made from cochineal powder which is derived from ground-up dried insects and larvae (Dactylopius coccus costa).

Many interesting details concerning the history and uses of carmine dye have recently appeared (U.S. Department of Health, Education and Welfare, National Office of Vital Statistics, 1966; Lang et al., 1967; Komarmy, Oxley, and Brecher, 1967). It appears that most processed batches of carmine are relatively safe for oral use. Newly received supplies should be cultured before use. Alternatively, synthetic brilliant blue (Lutwak and Burton, 1964) may be employed.

Alex J. Steigman

Professor of Pediatrics,

Mount Sinai School of Medicine,

Fifth Avenue and 100th Street,

New York,

N.Y. 10029, U.S.A.

REFBRBNCES

Komarmy, L. E., Oxley, M. E., and Brecher, G. (1967). Hospitalacquired salmonellosis traced to carmine-dye capsules. New England Fournal of Medicine, 276, 850-852.

Lang, D. J., Kunz, L. J., Martin, A. R., Schroeder, S. A., and Thomson, L. A. (1967). Carmine as a source of nosocomial salmonellosis. New England Fournal of Medicine, 276, 829-832.

Lutwak, L., and Burton, B. T. (1964). Fecal dye markers in metabolic balance studies; the use of brilliant blue and methylcellulose for accurate separation of stool periods. American fournal of Clinical Nutrition, 14, 109-111.

U.S. Department of Health, Education and Welfare, National Office of Vital Statistics (1966). Vital Statistics of the United States, vol. 15. Morbidity and Mortality Report. Washington D.C. August 20, 1966, p. 282 